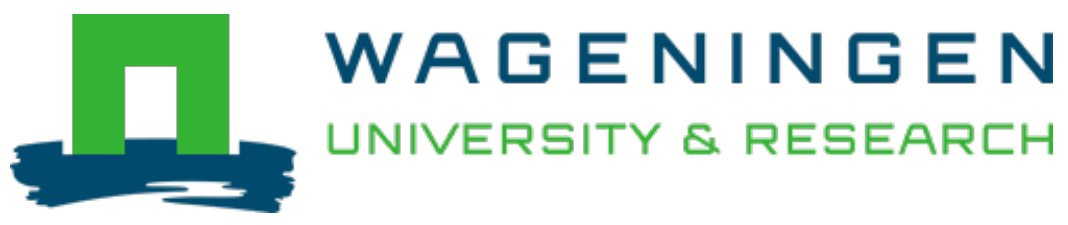

\author{
A Chinese fermented soybean food \\ International Journal of Food Microbiology \\ Han, B.Z.; Rombouts, F.M.; Nout, M.J.R. \\ https://doi.org/10.1016/S0168-1605(00)00523-7
}

This publication is made publicly available in the institutional repository of Wageningen University and Research, under the terms of article $25 \mathrm{fa}$ of the Dutch Copyright Act, also known as the Amendment Taverne. This has been done with explicit consent by the author.

Article $25 \mathrm{fa}$ states that the author of a short scientific work funded either wholly or partially by Dutch public funds is entitled to make that work publicly available for no consideration following a reasonable period of time after the work was first published, provided that clear reference is made to the source of the first publication of the work.

This publication is distributed under The Association of Universities in the Netherlands (VSNU) 'Article $25 \mathrm{fa}$

implementation' project. In this project research outputs of researchers employed by Dutch Universities that comply with the legal requirements of Article $25 \mathrm{fa}$ of the Dutch Copyright Act are distributed online and free of cost or other barriers in institutional repositories. Research outputs are distributed six months after their first online publication in the original published version and with proper attribution to the source of the original publication.

You are permitted to download and use the publication for personal purposes. All rights remain with the author(s) and / or copyright owner(s) of this work. Any use of the publication or parts of it other than authorised under article $25 \mathrm{fa}$ of the Dutch Copyright act is prohibited. Wageningen University \& Research and the author(s) of this publication shall not be held responsible or liable for any damages resulting from your (re)use of this publication.

For questions regarding the public availability of this publication please contact openscience.library@wur.nl 


\title{
Review
}

\section{A Chinese fermented soybean food}

\author{
Bei-Zhong Han ${ }^{\mathrm{a}, \mathrm{b}}$, Frans M. Rombouts ${ }^{\mathrm{a}}$, M.J. Robert Nout ${ }^{\mathrm{a}, *}$ \\ ${ }^{a}$ Laboratory of Food Microbiology, Department of Agrotechnology and Food Sciences, Wageningen University, \\ P.O. Box 8129, 6700 EV Wageningen, The Netherlands \\ ${ }^{\mathrm{b}}$ College of Food Science and Engineering, China Agricultural University, Beijing 100083, People's Republic of China
}

Received 11 March 2000; received in revised form 19 September 2000; accepted 7 December 2000

\begin{abstract}
Sufu or furu is a fermented soybean product originating in China. It is a cheese-like product with a spreadable creamy consistency and a pronounced flavour. Sufu is a popular side dish consumed mainly with breakfast rice or steamed bread. It has a long history and written records date back to the Wei Dynasty (220-265 AD). Sufu is made by fungal solid state fermentation of tofu (soybean curd) followed by aging in brine containing salt and alcohol. The present review is based on scientific data published in Chinese and international sources. Several types of sufu can be distinguished, according to processing method or according to colour and flavour. Choice of processing can result in mould fermented sufu, naturally fermented sufu, bacterial fermented sufu, or enzymatically ripened sufu. Depending on the choice of dressing mixture, red, white or grey sufu may be obtained. The stages of the process are discussed and include the preparation of tofu, the preparation of pehtze, salting and ripening. Fungal starters include Actinomucor spp., Mucor spp. and Rhizopus spp. The chemical composition is discussed with particular reference to the proximate composition, the amino acid content and profile, as well as the volatile flavour components of various types of sufu. (C) 2001 Elsevier Science B.V. All rights reserved.
\end{abstract}

Keywords: Chinese; Soybean; Food

\section{Introduction}

Over the centuries, the Chinese have used microorganisms to convert agricultural commodities into fermented food (Chen, 1989). These fermented foods have improved the quality of the diets of Chinese people and also enriched dishes all over the world. Traditional Chinese fermented foods cover a

\footnotetext{
* Corresponding author. Tel.: +31-317-482834; fax: +31-317484893.

E-mail address: rob.nout@micro.fdsci.wau.nl (M.J.R. Nout).
}

wide range of products, such as soy sauce, sufu, vinegar, distilled spirits, rice wine, fermented vegetable and meat products.

Sufu, Fu-ru written in hieroglyphics, is a fermented soybean curd and a highly flavoured, soft creamy cheese-type product which can be used in the same way as cheese ( $\mathrm{Su}, 1986)$.

Sufu is the name for the product that first appeared in the literature (Wang and Hesseltine, 1970). Literally, sufu $(f u-r u)$ means "moulded milk" and tosufu (dou-fu-ru) means "moulded soymilk". Because of the numerous dialects used in China and the 
difficulties of phonetic translation from Chinese into English, sufu has appeared in literature under many different names. The following synonyms for sufu in the literature have been found: sufu, tosufu, fu-ru, dou-fu-ru, tou-fu-ru, toe-fu-ru, jiang-dou-fu, fu-yu, and foo-yue. Sufu is also known as tofuyo, nyu-fu or fu-nyu in Japan (Yasuda and Kobayashi, 1989), chao in Vietnam, ta-huri in the Philippines, taokaoan in Indonesia and tao-hu-yi in Thailand (Beuchat, 1995). These names confuse Western people as well as the Chinese. Officially, sufu should be named Furu (or Doufuru) in Chinese.

Manufacture of tofu (soybean curd) began during the era of the Han Dynasty. The Ben-Cao-Gang-Mu (Chinese Materia Medica), compiled by Li Shi-zhen in 1597, indicated that tofu was invented by Liu An (179-122 BC), King of Weinan (Steinkraus, 1996; Shi and Ren, 1993). However, it is not known when sufu production began. Due to the long history and incomplete written records, no attempt was made to search for its origin. The first historical record mentioned that the sufu process was carried out in the Wei Dynasty (220-265 AD) (Wang and Du, 1998; Hong, 1985). It became popular in the Ming Dynasty (1368-1644), and there are many books describing sufu processing technologies (Zhang and Shi, 1993).

Sufu products are manufactured both commercially and domestically, and the annual production is estimated over 300,000 metric tons in China. Sufu is

Table 1

Proximate composition of commercial sufu

\begin{tabular}{lc}
\hline Component & Content $^{\mathrm{a}}$ \\
\hline Moisture $(\mathrm{g})$ & $58-70$ \\
Crude protein $(\mathrm{g})$ & $12-17$ \\
Crude lipid $(\mathrm{g})$ & $8-12$ \\
Crude fibre $(\mathrm{g})$ & $0.2-1.5$ \\
Carbohydrate $(\mathrm{g})$ & $6-12$ \\
Ash $(\mathrm{g})$ & $4-9$ \\
Calcium $(\mathrm{mg})$ & $100-230$ \\
Phosphorus $(\mathrm{mg})$ & $150-300$ \\
Iron (mg) & $7-16$ \\
Thiamin $\left(\mathrm{V}_{\mathrm{B} 1}\right)(\mathrm{mg})$ & $0.04-0.09$ \\
Riboflavin $\left(\mathrm{V}_{\mathrm{B} 2}\right)(\mathrm{mg})$ & $0.13-0.36$ \\
Niacin $(\mathrm{mg})$ & $0.5-1.2$ \\
$\mathrm{~V}_{\mathrm{B} 12}(\mu \mathrm{g})$ & $1.7-22$ \\
Food energy $(\mathrm{KJ})$ & $460-750$ \\
\hline
\end{tabular}

Sources: Wang and Du (1998) and Su (1986).

${ }^{\mathrm{a}}$ Per $100 \mathrm{~g}$ sufu fresh weight. consumed as an appetizer and a side dish, e.g. with breakfast rice or steamed-bread. Sufu adds zest to the bland taste of the rice and flour diet. Since it is made from soybeans and is an easily digested and nutritious protein food, Chinese people consider it a health food. The food encyclopedia written by Wang (1861) in the Qing Dynasty described the food as follows: "Hardened tofu is difficult to digest and not healthy for children, elderly persons or ill persons. Sufu fermented from tofu is better because it is matured and very good for patients." Sufu is a highly flavored, creamy cheese-like product, so it would be expected to be suitable for use in western countries as a healthy, non-cholesterol food from plant origin. Table 1 summarizes some major chemical constituents of sufu.

\section{The classification of sufu}

There are many different types of sufu, which are produced by various processes in different localities in China (Li, 1997; Wang and Du, 1998).

(1) Four types of sufu can be distinguished according to the processing technologies. The base for all form types is tofu, a curd from soybean milk by adding Calcium salts.

(1.1) Mould-fermented sufu: Four steps are normally involved in making this type of sufu; (1) preparing tofu, (2) preparing pehtze (pizi) with a pure culture mould fermentation, (3) salting, (4) ripening (see innovated commercial process).

(1.2) Naturally fermented sufu: Four steps are also normally involved in making this type of sufu; (1) preparing tofu, (2) preparing pehtze (pizi) with natural fermentation, (3) salting, (4) ripening (see traditional process with natural fermentation).

(1.3) Bacteria-fermented sufu: Five steps are normally involved in making this type of sufu; (1) preparing tofu, (2) pre-salting, (3) preparing pehtze (pizi) with a pure culture bacterial fermentation, (3) salting, (4) ripening. During the pre-salting, the tofu adsorbs the salt till the salt content of tofu reaches about $6.5 \%$, which takes about 2 days. Pehtze is prepared by pure cultured Bacillus spp. or Micrococcus spp. at $30-38^{\circ} \mathrm{C}$ for about 1 week. In order to keep the shape of the final product, pehtze is dried at 
$50-60^{\circ} \mathrm{C}$ for $12 \mathrm{~h}$ before salting. The ripening time normally takes less than 3 months. This sufu is made in some places, such as Kedong (Heilongjiang) and Wuhan (Hubei).

(1.4) Enzymatically ripened sufu: Three steps are normally involved in making this type sufu; (1) preparing tofu, (2) salting, and (3) ripening. Because there is no fermentation before ripening, some koji is added in the dressing mixture for enzymatic ripening. The ripening time takes $6-10$ months. This product of sufu is produced only in a few areas of China, such as Taiyuan (Shanxi) and Shaoxin (Zhejiang).

(2) According to the colour and flavour, sufu can be classified into four types, which are mainly based on the different ingredients of dressing mixtures in the ripening stage.

(2.1) Red sufu (see Fig. 1): The dressing mixture of red sufu mainly consists of salt, angkak (red kojic rice), alcoholic beverage, sugar, flour (or soybean) paste and some spices. The outside colour of the sufu is from red to purple, and the interior colour is from light yellow to orange. Because red sufu possesses an attractive colour and strong flavour, it is the most popular product all over China.

Angkak (Anka, Red kojic rice or Red Qu) is a product produced by solid-substrate fermentation of cooked rice with various strains of Monascus spp., such as M. purpureus. It has a specific aroma and purple red colour and has been used as a natural colorant in red sufu and some other traditional food.

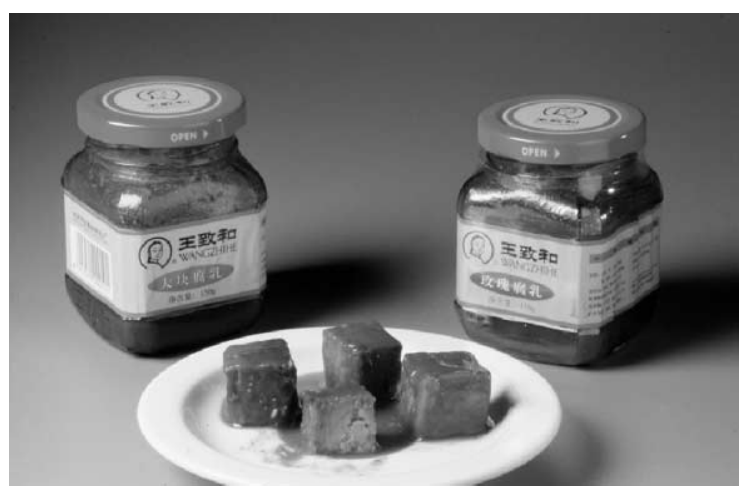

Fig. 1. Red sufu.
(2.2) White sufu: White sufu has similar ingredients as red sufu in the dressing mixture but without angkak. It has an even light yellow colour inside and outside. White sufu is a popular product in the south of China because it is less salty than red sufu.

(2.3) Grey sufu: The dressing mixture of grey sufu contains the soy whey left over from making tofu, salt and some spices. Grey sufu is ripened with a special dressing mixture, which could be dominated by both bacteria and mould enzymes and results in a product with a strong, offensive odour. The preparation of this type of sufu is a top secret in the industry and is slowly becoming a lost art (Wang and Fang, 1986).

(2.4) Other types: Other sufu types are made by adding various ingredients to the dressing, including vegetables, rice, bacon, and even higher concentrations of alcohol. For instance, dressing mixture containing high levels of ethanol results in a product having a marked alcoholic bouquet. This product is called Zui-Fang (or tsui-fang), which means drunk sufu.

(3) Sufu can be also classified according to size, such as big sufu and small sufu, and shape, square sufu and chess (round) sufu (Huang, 1991).

\section{Manufacturing process}

Most sufu products are produced by a similar principle, which involves four main steps: (1) preparation of tofu; (2) preparation of pehtze; (3) salting; and (4) ripening. The schematic diagram for production of sufu is shown in Fig. 2 (Nout and Aidoo, 2000).

\subsection{Traditional process with natural fermentation}

Traditionally, the preparation of sufu is a centuries-old household activity involving natural fermentation. The process is still used in some places, such as Jiangsu and Zhejiang (Wang and Du, 1998).

\subsubsection{Preparation of tofu}

Soybeans are washed and soaked overnight in water, and then ground in a stone mill into a slurry. 




Fig. 2. The schematic diagram for production of sufu.

The slurry is diluted and pressed to obtain soymilk. Coagulation is achieved by acid or by addition of salts, such as calcium sulphate and magnesium sulphate. The precipitate is pressed to remove excess water (soy whey) with cheesecloth bags using stones or wooden planks. Finally, a soft but firm cake-like tofu results, which can then be cut into cubes of desired sizes.

\subsubsection{Preparation of pehtze (pizi)}

Pehtze (see Fig. 3), fresh bean curd overgrown with mould mycelia, is prepared by means of natural fermentation. Cubes of tofu are placed in wooden trays, the bottom of which is made of bamboo strips loosely woven together. The loaded trays are piled up and surrounded with straw for natural inoculation and fermentation. The temperature is $15-20^{\circ} \mathrm{C}$, which is not favourable for bacteria, yeasts and other moulds except for Mucor spp. This step takes 5-15 days and varies depending on locality and season.
The pehtze must have white or light yellow-white mycelium to ensure that the final sufu has an attractive appearance. Before the pehtze is moved to the salting treatment, the mycelial mat of mould should be flattened by hand so that a firm film will be formed over the surface of the sufu to keep its shape.

\subsubsection{Salting}

The pretreated pehtze is transferred into a big earthen jar and salt is spread between layers of pehtze as they pile up in the jar. During this period, the pehtze adsorbs the salt until salt content of pehtze reaches about $16 \%$, which takes 6-12 days. The salted pehtze is removed from the jar, washed with water, and then transferred to another jar for further processing.

\subsubsection{Ripening}

The differences between the various types of sufu are mainly caused during the ripening process since different dressing mixtures are added in salted pe-

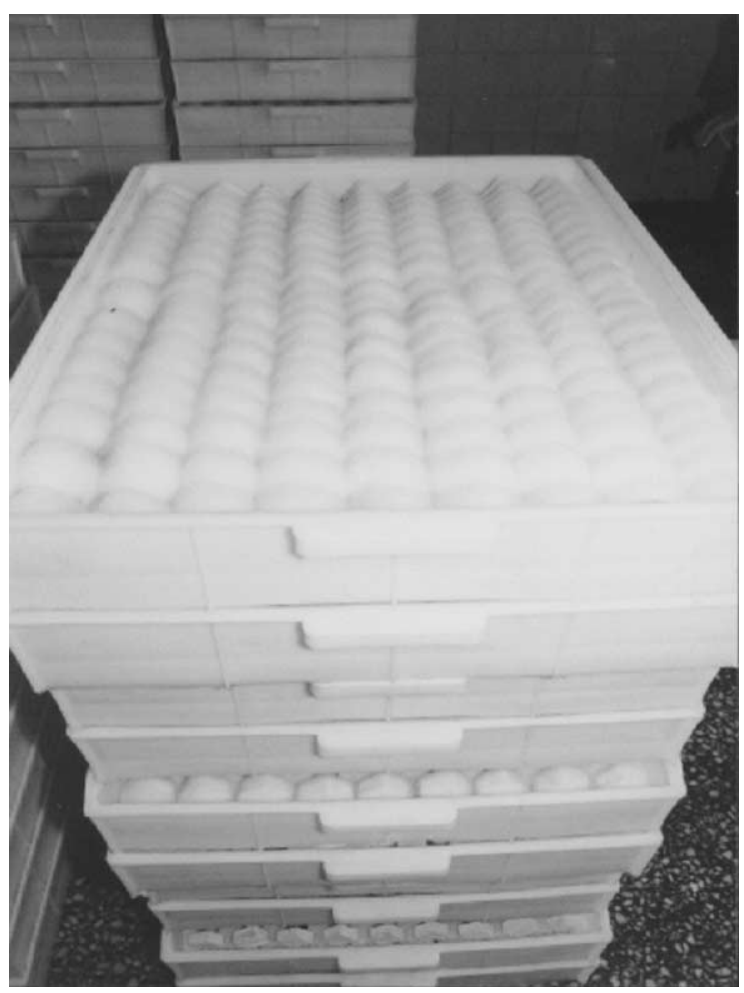

Fig. 3. Pehtze. 
htze. The ingredients of dressing mixture vary with social customs, climate, locations and so on. The most common dressing mixture used consists of angkak, alcoholic beverage, salt, sugar, flour (or bean) paste, and spices. Additional essence can be added into the dressing mixture to supply a special flavour.

For the ripening, alternate layers of pehtze and dressing mixture are packed into jars, and the ratio is about $2: 1$ between salted pehtze and dressing mixture. The mouth of the jar is wrapped with sheath leaves of bamboo and sealed with clay. The sealed jars are aged for 6 months for further maturation.

\subsection{Innovated commercial process}

Nowadays, sufu is manufactured at an industrial scale, following the same four main steps as the traditional process.

\subsubsection{Preparation of tofu}

The production of tofu is highly mechanized. The yield and quality of commercial tofu are affected by soybean composition (Murphy et al., 1997), soymilk characteristics (Lim et al., 1990), coagulant, and other factors (Moizuddin et al., 1999). Preparation of tofu used for sufu mainly follows the process technologies for commercial tofu except for slight differences in some steps. First, soybeans of selected quality are washed and ground with added water to a milky slurry in a steel mill. The slurry is then heated and filtered through cloth to separate soymilk. Coagulation is done at $70-80^{\circ} \mathrm{C}$ by addition of calcium sulphate and magnesium sulphate. Generally, 20\% more coagulant is used to produce tofu for sufu than for regular tofu production. Coagulant added is $2.5-$ $3.5 \%$ of the dry starting weight of soybean. Moreover, after the calcium salts are mixed with soymilk, the mixture needs to be agitated vigorously in order to get a homogenous coagulum, and then it is set aside for $10-15 \mathrm{~min}$ to complete the coagulation. The precipitate is pressed to remove excess water (soy whey) with cheese-cloth in a mechanized press. Finally, a soft, cake-like tofu results which can then be cut into desired sizes (normally rectangular pieces, approximately $3.2 \times 3.2 \times 1.6 \mathrm{~cm})$. Moisture and $\mathrm{pH}$ of tofu are $70-79 \%$ and $6-7$, respectively, varying with the type of sufu to be produced (Wang and Du, 1998; Li, 1998).

\subsubsection{Preparation of pehtze (pizi)}

Pehtze (or pizi), fresh bean curd overgrown with mycelium of moulds is produced by means of solidsubstrate fermentation after inoculation with pure culture moulds. The process of making pehtze was considered a natural phenomenon until 1920, when a microorganism believed to be responsible for sufu fermentation was isolated and identified ( $\mathrm{Su}, 1986)$. Wei (1928) studied the microorganisms found in sufu and isolated a pure culture strain of Mucor from the fermenting pehtze samples.

3.2.2.1. Microorganisms. The fungal genera involved (Actinomucor, Mucor and Rhizopus) all belong to the Mucoraceae. The mould used in fermentation of sufu is critical and has to possess certain characteristics. First of all, the mould must have enzyme systems with high proteolytic and lipolytic activities since it grows on tofu that is a protein and lipid-rich and carbohydrate-poor medium. Secondly, the mould must have white or, at most, slightly yellowish white mycelium to ensure that the sufu has an attractive appearance. Thirdly, the texture of the mycelial mat should be dense and tenacious so that a film formed on the surface of the pehtze will act as an over-casing to protect the final product of sufu from deformation. Finally, the mould growth should not develop any off-odor, astringent taste, or mycotoxins and the mould should resist undesired bacterial contamination during the fermentation.

Some Mucor spp., Actinomucor spp., and Rhizopus spp. fulfill all of these criteria and could be used for making high-quality sufu. Among them, Actinomucor elegans and Actinomucor taiwanensis seem to be the best moulds that are used for pehtze production commercially in Beijing and Taiwan, respectively. However, also other moulds such as $\mathrm{Mu}$ cor sufu and Mucor wutungkiao have been mentioned as popular starter cultures. Nevertheless, most of Actinomucor spp. and Mucor spp. only grow well at $20-30^{\circ} \mathrm{C}$, so it is hard to produce sufu during the hot summer (Hu and Zhao, 1998a). Hu and Zhao (1998b) and Deng et al. (1996) screened mutants, made by using conventional mutagens and isolated 
strains of Mucor sp. $\mathrm{M}_{263}$ and Mucor sp. $\mathrm{H}_{4}$, which could grow at $30-40^{\circ} \mathrm{C}$ and ensure sufu production all year round. The authors did not provide information about the stability and safety of these mutants.

3.2.2.2. Inoculation. A pure culture inoculum of mould can be prepared, starting from agar slant culture, by liquid or solid substrate culture in roux bottles. The medium used for solid-substrate culture consists of bran and water (1:1.2-1.4) and that for liquid-substrate culture contains soy whey with added maltose $(2-3 \%)$ and peptone $(1.5-2.0 \%)$. The spore suspension $\left(\sim 10^{5} \mathrm{CFU} / \mathrm{ml}\right)$ is harvested and inoculated on the surfaces of the tofu with manually operated sprayers, comparable to those used for spraying plants.

\subsubsection{Incubation. The inoculated tofu is placed,} evenly spaced in wooden or plastic trays, the bottoms of which are made of bamboo or wooden strips. The loaded trays are piled up in an incubation room, where a controlled temperature (about $25^{\circ} \mathrm{C}$ ), a relative humidity (88-97\%) and good aeration are needed for optimum growth of the mycelia. The thin white mycelia are developed in $8-12 \mathrm{~h}$ and a thick mycelial mat is formed after $36-40 \mathrm{~h}$ of incubation. Then the room temperature is decreased by aeration to prevent over-growth of mould, until a slightly yellowish white color appears, at which point formation of fresh pehtze is complete. The total cultivation time is about $48 \mathrm{~h}$, which is much less than in the traditional way (5-15 days).

Chou et al. (1988) reported that the incubation temperature, humidity, and cultivation time greatly affected the growth of and enzyme production by $A$. taiwanensis on tofu. Optimum conditions observed for growth of A. taiwanensis were $25-30^{\circ} \mathrm{C}$ at $97 \%$ relative humidity when tofu of $65 \%$ moisture content was inoculated. Under these conditions, a maximum production of protease, lipase, $\alpha$-amylase and $\alpha$ galactosidase was achieved.

Before pehtze is transferred to the salt treatment, the mould mycelial mat should be flattened by hand, in the same way as done in the traditional way.

\subsubsection{Salting}

Freshly prepared pehtze has a bland taste. The flavour and aroma of sufu develop during the salting and ripening process. During the salting period, the pehtze absorbs salt and loses water until the salt content reaches a certain equilibrium level. The absorbed salt imparts a salty taste to the sufu, and it retards further mould growth, and the growth of undesirable microbial contaminants. The added salt also plays another important role in releasing the mycelia-bound proteases. Wang and Hesseltine (1970) mentioned that the fungal proteases were not extracellular and that they are loosely bound to the mycelium, possibly by ionic linkage. On the other hand, the mould grows just on the surfaces of the tofu pieces, and the mycelium hardly penetrates into the tofu. The salting could enable the enzymes to diffuse into the tofu for substrate degradation.

Pehtze can be salted in many ways, e.g.:

(I) The pehtze is transferred to containers, each having a volume of 10-20 1 and each layer of pehtze being sprinkled with a layer of salt in accordance with a traditional method. This method not only takes longer, but also the pieces of pehtze have widely varying salt concentration.

(II) The pehtze is transferred to vessels containing a saturated salt solution. After 4-5 days at room temperature, the salt content of the pehtze can reach over $12 \%$ and the moisture content decreased by $10-15 \%$. Final levels of moisture content may vary in the range $50-65 \%(\mathrm{w} / \mathrm{w})$.

(III) Pehtze is immersed in an alcoholic saline solution consisting of $12 \% \mathrm{NaCl}$ and $10 \%$ ethanol (distilled liquor or rice wine is used). Pehtze immersed in this solution can be sold as such. Actually, this method combines the salting and the ripening together in one step.

\subsubsection{Ripening}

The flavour and aroma of sufu develop during the ripening step. During this period, the enzymes produced by the mould act upon their respective substrates, and it is likely that hydrolysis of protein and lipid provide the principal compounds of the mild, characteristic flavour of sufu. The soybean proteins are hydrolysed by the proteinases into peptides and amino acids. Free amino acids, such as glutamic acid, aspartic acid, leucine/isoleucine and alanine, are predominant in sufu (Table 2). The pleasant and palatable taste is considered to be related to the content of free amino acids, mainly glutamic acid, in 
Table 2

Amino acid content of sufu samples

\begin{tabular}{|c|c|c|c|c|}
\hline Amino acid & $\begin{array}{l}\text { Red sufu }{ }^{a} \\
\text { (g/100 g sufu) }\end{array}$ & $\begin{array}{l}\text { Grey sufu }{ }^{a} \\
\left(g / 100 g_{\text {sufu}}\right)\end{array}$ & $\begin{array}{l}\mathrm{Sufu}^{\mathrm{b}} \\
(\mathrm{g} / 100 \mathrm{~g} \text { protein })\end{array}$ & $\begin{array}{l}\text { White sufuc } \\
(\text { Molar ratio \%) }\end{array}$ \\
\hline Alanine & 0.32 & 0.70 & 10.0 & 7.0 \\
\hline Arginine & 0.38 & 0.27 & 2.1 & 2.5 \\
\hline Aspartic acid & 1.00 & 0.66 & 5.1 & 13.7 \\
\hline Cystine & 0.59 & 0.20 & 0.4 & \\
\hline Glutamic acid & 2.15 & 2.08 & 0.6 & 22.0 \\
\hline Glycine & 0.54 & 0.42 & 4.4 & 7.0 \\
\hline Histidine & 0.20 & 0.18 & 1.4 & 1.9 \\
\hline Isoleucine & 0.88 & 0.58 & 4.8 & 4.5 \\
\hline Leucine & 0.81 & 0.95 & 8.8 & 7.6 \\
\hline Lysine & 0.59 & 0.29 & 7.0 & 7.3 \\
\hline Methionine & 0.51 & 0.14 & 0.7 & \\
\hline Phenylalanine & 0.59 & 0.59 & 4.6 & 2.6 \\
\hline Proline & 0.38 & 0.29 & 2.4 & 7.7 \\
\hline Serine & 0.34 & 0.27 & 2.3 & 5.2 \\
\hline Threonine & 0.45 & 0.23 & 2.0 & 4.1 \\
\hline Tryptophan & 0.09 & 0.05 & 0.6 & \\
\hline Tyrosine & 0.54 & 0.25 & 2.2 & 1.0 \\
\hline Valine & 0.16 & 0.58 & 5.3 & 5.2 \\
\hline
\end{tabular}

${ }^{\mathrm{a}}$ Wang (1995) and Wang and Du (1998).

${ }^{\mathrm{b}} \mathrm{Su}$ (1986): commercial sample non-specified.

${ }^{\mathrm{c}}$ Liu and Chou (1994).

oriental fermented food (Chou et al., 1993). Purification and some properties of glutaminase (catalyses hydrolysis of glutamine to glutamate) from A. taiwanensis were studied by Lu et al. (1996). Glutaminase was stable at a temperature up to $35^{\circ} \mathrm{C}$ and at $\mathrm{pH}$ values of 6.0-8.0. In the presence of $10 \% \mathrm{NaCl}$, the enzyme activity was inhibited $50 \%$.

Soybean lipids are also hydrolysed to some extent into fatty acids. The added alcohol reacts with the fatty acids chemically or enzymatically to form esters, providing the pleasant odor of the product. The alcohol also retards the degradation of soybean proteins (Chou and Hwan, 1994). A higher protein solubility and a higher content of peptides and amino acids were observed in the sufu ripened in a brine solution without ethanol.

Salted pehtze is ripened in various jars or bottles, ranging in size from approximately $0.25-101$, containing a dressing mixture that varies with the type of sufu. The dressing mixture that is most commonly used for red sufu includes salt (final salt content 10-12\%), angkak (red kojic rice) $2 \%$, flour (or soybean) paste $3-5 \%$, alcohol content $8-12 \%$, sugar $5-10 \%$ and some spices. Additional essence is also added to the dressing mixture to supply a special flavour. For instance, rose essence is added to the dressing mixture for Rose Sufu preparation. The addition of hot pepper to a dressing mixture would make Hot Sufu. Therefore, the flavour and aroma of sufu, in addition to its own characteristics can be easily improved or modified by the ingredients of the dressing mixture.

Ripening requires much time and space. Although nowadays the ripening time is shorter than the 6 months that the traditional process took, modern processes still take about 2-3 months. Reduction of ripening times can be achieved by using smaller cubes of tofu, lowering the salt content from $\sim 14 \%$ to $\sim 10 \%$, lowering alcohol content from $\sim 10 \%$ to $\sim 6 \%$, keeping the ripening temperature at a higher and more constant level, and using smaller jars. The high concentrations of salt are considered to retard the hydrolysis of protein and lipid. In addition, human consumption of sufu is also limited because of its saltiness. Unfortunately, lowering salt content could cause other problems, such as shorter shelf-life. In an attempt to overcome the problem, a coating of whole blocks of pehtze with paraffin (m.p. $60^{\circ} \mathrm{C}$ ) 
was studied (Wai, 1964). The pehtze was first mixed with salt (7\% of pehtze weight) and then coated with a layer of melted paraffin. Upon solidification of the paraffin, the product was stored in a glass container. After 1 month at room temperature, the paraffin layer was removed and the contents were subjected to sensory evaluation. The resultant sufu was found to be satisfactory. In order to accelerate the ripening of sufu, stem bromelain was used as a coagulant of soymilk and a hydrolytic enzyme (Fuke and Matsuoka, 1984). Increases in ripening rate and enhanced flavour were obtained by the addition of stem bromelain.

From the microbiological point of view, it may be expected that yeasts and bacteria play a role in the flavour and texture of sufu. Little literature is available on these issues, except a study on the halophilic flora of sufu. Pao (1995) reported that high levels of non-halophiles and moderate halophiles were found in $60 \%$ of sufu brands tested. Predominant halophiles were identified as Tetragenococcus halophila (previously Pediococcus halophilus).

\section{Chemical composition and nutritional quality of sufu}

From a nutritional point of view, sufu has a higher content of protein-nitrogen than other oriental soybean foods, such as miso and natto ( $\mathrm{Su}, 1986)$. Nutritionally, soybean milk, tofu and sufu have the same importance to people of Asia as cows milk and cheese do to the people of the Western Hemisphere. Asians prefer the salt-coagulated bean curd, not only because it has the desired texture, but also because it serves as an important source of calcium (Wang and Hesseltine, 1970; Zhao, 1997).
The chemical and nutritional compositions of sufu are shown in Table 1 (Li, 1998; Wang and Du, 1998; $\mathrm{Su}, 1986)$. In spite of their differences in colour and flavour, most types of sufu have a similar proximate composition.

The amino acid content of sufu is presented in Table 2 (Wang, 1995; Wang and Du, 1998; Liu and Chou, 1994; Su, 1986). Glutamic acid and aspartic acid were the most abundant amino acids found in red sufu and grey sufu. The ratio of (glutamic acid + aspartic acid):(total amino acid content) was around $30 \%$, which provides sufu with a delicious taste. The cystine and methionine contents of grey sufu may be lower than those of red sufu because of their degradation or conversion to other sulfur compounds during maturation, which may contribute to the offensive odor of grey sufu.

Yen (1986) reported that the average amine contents in 15 samples of commercial sufu from Taiwan, China were: cadaverine $(0.039 \mathrm{mg} / \mathrm{g})$, histamine $(0.088 \mathrm{mg} / \mathrm{g})$, beta-phenylethylamine $(0.063 \mathrm{mg} / \mathrm{g})$, putrescine $(0.473 \mathrm{mg} / \mathrm{g})$, tryptamine $(0.150 \mathrm{mg} / \mathrm{g})$, and tyramine $(0.485 \mathrm{mg} / \mathrm{g})$. Tyramine and putrescine were the major amines found, and these might have a potential harmful effect on human beings if levels are very high.

The complex flavour of sufu was reported to contain 22 esters, 18 alcohols, 7 ketones , 3 aldehydes, 2 pyrazines, 2 phenols and other volatile compounds by Hwan and Chou (1999). Maturation in the presence of ethanol resulted in higher levels of volatiles. Ho et al. (1989) compared the volatile flavor compounds of red sufu and white sufu. Red sufu contains much larger amounts of alcohols, esters, and acids, which may be due to the fermentation of angkak by Monascus spp. The esters give red sufu its characteristic fruity aroma. White sufu con-

Table 3

Volatile compounds detected in red/white types of sufu

\begin{tabular}{ll}
\hline Alcohols & Ethanol, 2-Butanol, Propanol, 2-Methylpropanol, Butanol, 3-Methylbutanol, Hexanol, 3-Octanol, \\
& 2-Ethylhexanol, Benzyl alcohol, Phenylethyl alcohol \\
Ethyl butyrate, Ethyl 2-methylbutyrate, Ethyl hexanoate, Ethyl heptanoate, Ethyl octanoate, \\
Ethyl benzoate, Ethyl dodecanoate, Phenylethyl propanoate, Ethyl tetradecanoate, Ethyl palmitate, \\
Ethyl stearate, Ethyl oleate, Ethyl linoleate \\
Miscellaneous & Acetic acid, Phenol, 2-Nonanone, 2,6-Dimethylpyrazine, 2-Ethyl-5-methylpyrazine
\end{tabular}

Sources: Ho et al. (1989) and Hwan and Chou (1999). 
tains a large quantity of anethol, which seems to be the major contributor of its flavour. The volatile compounds detected in red/white types of sufu are shown in the Table 3.

\section{Conclusion}

To provide the increasing global population with a source of protein other than meat is a worldwide challenge. Alternative sources are legumes and cereals. But plant protein by itself often lacks desirable flavours. To overcome this deficiency, fermentation can either add desirable flavour or destroy unpleasant flavour. This is especially true in soybean products made by fermentation.

In China, sufu is one of the most important traditional fermented soybean foods. It has been widely consumed as a relish by Chinese people for more than 1000 years, and further, it can be used in the same way as cheese. Throughout history, the Chinese seemed to follow their own ways in developing the product without foreign influences. Although a pure culture method for preparing sufu has been developed, further studies are still needed to guarantee uniform high quality products. If innovations in taste, flavour and product quality are made, sufu may become more widely popular all over the world.

\section{References}

Beuchat, L.R., 1995. Indigenous fermented foods. In: Reed, G., Nagodawithana, T.W. (Eds.), Enzymes, Biomass, Food and Feed. Biotechnology, vol. 9. VCH Press, Weinheim, pp. 523525.

Chen, T.-S., 1989. Past, present and future of Chinese fermented food products. Food Rev. Int. 5 (2), 177-208.

Chou, C.-C., Ho, F.-M., Tsai, C.-S., 1988. Effects of temperature and relative humidity on the growth and enzyme production by Actinomucor taiwanensis during sufu pehtze preparation. Appl. Environ. Microbiol. 54 (3), 688-692.

Chou, C.-C., Hwan, C.-H., 1994. Effect of ethanol on the hydrolysis of protein and lipid during the ageing of a Chinese fermented soya bean curd-sufu. J. Sci. Food Agric. 66, 393 398.

Chou, C.-C., Yu, R.-C., Tsai, C.-S., 1993. Production of glutaminase by Actinomucor elegens, A. taiwanensis and Aspergillus oryzae. J. Chin. Agric. Chem. Soc. 31, 78-86 (in Chinese, with English abstract).
Deng, F.-X., Weng, Q.-Y., Lu, X.-C., Liu, S.-C., 1996. Screening of thermo-tolerant strain of Mucor sp. for sufu production. J. China Brew. Ind. 1, 27-31 (in Chinese).

Fuke, Y., Matsuoka, H., 1984. Preparation of fermented soybean curd using stem promelain. J. Food Sci. 49, 312-313.

Ho, C.-T., Zhang, Y.-G., Shi, H., Tang, J., 1989. Flavour chemistry of Chinese food. Food Rev. Int. 5 (3), 253-287.

Hong, G.-Z., 1985. The history of sufu. J. China Brew. Ind. 1, 44-45 (in Chinese).

Hu, D., Zhao, X.-H., 1998a. Physiology of thermo-tolerant strain of Mucor sp. $\mathrm{H}_{4}$. J. China Brew. Ind. 5, 24-26 (in Chinese).

$\mathrm{Hu}$, D., Zhao, X.-H., 1998b. The screening of thermo-tolerant strain of Mucor spp. J. Chin. Seasonings 1, 2-6 (in Chinese).

Huang, Z.-H. (Ed.) 1991. Handbook of Chinese Seasonings Process Technology. China Standards Press, Beijing, China, pp. 602-611 (in Chinese).

Hwan, C.-H., Chou, C.-C., 1999. Volatile components of the Chinese fermented soya bean curd as affected by the addition of ethanol in ageing solution. J. Sci. Food Agric. 79, 243-248.

Li, Y.-J., 1997. Sufu-a health soybean food. J. China Brew. Ind. 4, 1-4 (in Chinese).

Li, Y.-J., 1998. The modified process of sufu production. J. China Brew. Ind. 4, 6-11 (in Chinese).

Lim, B.T., DeMan, J.M., DeMan, L., Buzzell, R.I., 1990. Yield and quality tofu as affected by soybean and soymilk characteristics, calcium sulfate coagulant. J. Food Sci. 55 (4), 10881092, 1111.

Liu, Y.-H., Chou, C.-C., 1994. Contents of various types of proteins and water soluble peptides in sufu during aging and the amino acid composition of tasty oligopeptides. J. Chin. Agric. Chem. Soc. 32 (3), 276-283 (in Chinese, with English abstract).

Lu, J.-M., Yu, R.-C., Chou, C.-C., 1996. Purification and some properties of glutaminase from Actinomиcor taiwanensis, starter of sufu. J. Sci. Food Agric. 70, 509-514.

Moizuddin, S., Johnson, L.D., Wilson, L.A., 1999. Rapid method for determining optimum coagulant concentration in tofu manufacture. J. Food Sci. 64 (4), 684-687.

Murphy, P.A., Chen, H.P., Hauck, C.C., Wilson, L.A., 1997 Soybean protein composition and tofu quality. Food Technol. $51(3), 86-88,110$.

Nout, M.J.R., Aidoo, K.E., 2000. Asian fungal fermented food. In: Osiewacz, H.D. (Ed.), Industrial Applications. The Mycota, vol. X, In press.

Pao, S.C., 1995. Halophilic organisms in sufu, Chinese cheese. Diss. Abstr. Int., B 55 (10), 4190.

Shi, Y.-G., Ren, L. (Eds.) 1993. The Manufacturing Process of Soybean Products. China Light Industry Press, Beijing, China, pp. 4-9 (in Chinese).

Steinkraus, K.H. (Ed.) 1996. Chinese sufu. Handbook of Indigenous Fermented Foods. Marcel Dekker, New York, pp. 633641.

Su, Y.C., 1986. In: Reddy, N.R., Pierson, M.D., Salunkhe, D.K. (Eds.), Sufu. Legume-based Fermented Foods CRC Press, Boca Raton, FL, USA, pp. 69-83.

Wai, N.S., 1964. Soybean cheese. Bull. Inst. Chem., Acad. Sin. 9 , 74-94. 
Wang, 1861 cited in Wang, R.-Z., Du, X.-X., (Eds.) 1998. The Production of Sufu in China. China Light Industry Press, Beijing, China (in Chinese).

Wang, H.L., Fang, S.F., 1986. History of chinese fermented foods. In: Hesseltine, C.W., Wang, H.L. (Eds.), Indigenous Fermented Food of Non-Western Origin. J. Cramer Press, Berlin, pp. 23-35.

Wang, H.L., Hesseltine, C.W., 1970. Sufu and Lao-Chao. J. Agric. Food Chem. 18 (4), 572-575.

Wang, R.-Z., 1995. Sufu quality and ripening (postfermentation) control. J. China Brew. Ind. 2, 31-35 (in Chinese).

Wang, R.-Z., Du, X.-X. (Eds.) 1998. The Production of Sufu in China. China Light Industry Press, Beijing, China (in Chinese).

Wei, Y.-S., 1928. Mucor sufu in Chinese fermented bean curd. J. Agric. 1 (13), 1-2 (in Chinese).
Yasuda, M., Kobayashi, A., 1989. Preparation and characterization of Tofuyo (fermented soybean curd). In: Ang, H.G., Nga, B.H., Lim, K.K. (Eds.), Proceedings of the 7th World Congress of Food Science and Technology, Singapore October 1987. Trends in Food Biotechnology Singapore Institute of Food Science and Technology, pp. 82-86.

Yen, G.-C., 1986. Studies on biogenic amines in foods: I. Determination of biogenic amines in fermented soybean foods by HPLC. J. Chin. Agric. Chem. Soc. 24 (2), 211-227 (in Chinese, with English abstract).

Zhang, G.-Y., Shi, Y.-G., 1993. The history of sufu production. J. Food Ferment. Ind. 6, 72-74 (in Chinese).

Zhao, D.-A., 1997. Legend of sufu. J. China Brew. Ind. 5, 33-34 (in Chinese) 